\title{
Research on the Cultivation of Software Talents' Practical Ability Based on Campus Informatization Construction
}

\author{
Yuhua Chen and Jinghai Yin \\ Institute of Information Technology, Jiangxi University of Technology, Nanchang 330098, China
}

Keywords: Software personnel training; Campus informatization; Practical abilitys

\begin{abstract}
This paper explores a will practice ability of software talents training informatization construction and the combination of the teaching mode, to lower construction cost and cost management to improve the level of development of students and practical ability, but also to teacher training practice ability, reduce the cost of implementation of informatization construction in Colleges and universities.
\end{abstract}

\section{Introduction}

The rapid development of the software industry puts forward higher requirements for the cultivation of software talents.. But in the talent market in software, the software talents training structure and quality problems, the fundamental reason lies in training professionals in the fields which does not adapt with the industrial development, theory divorced from practice, practice is weak, disjointed problems are more serious. Experts in the education sector have carried out the relevant studies and have proposed their respective views. From the theory of cluster, the path of resource integration is pointed out, and some measures such as strengthening enterprise cooperation, establishing the cooperation group of the same training base, and constructing regional management mechanism and network platform are proposed.. Some points out from the cooperation between the school and enterprise, the common interests of the joint interests of the point of entry, and proposed a real project based on the operating mode of the school training base in the software professional school. There are also people from ten aspects of the modern enterprise management and engineering technology research center running double mode application of the computer training base in the application of the proposed. And explore the training base construction should make efforts to solve the problems, and put forward that government, colleges, enterprises should in engineering, combining to take more responsibility for education, the establishment of long-term mechanism to ensure that the base for sustainable development and closely rely on the IT industry, deepen the intramural productive training base construction and other measures. In general, experts in the field of education on practice base construction put forward many useful building ideas, patterns and methods, but these kinds of operation modes, there are some practical problems:

1. Through the cooperation between school and enterprise, in the enterprise to establish training base, this way often because enterprises can not gain much benefit, learning and training of the students don't care, if you want to create benefits for the enterprise, it must the actual development of commercial projects, but only a few students can immediately participate in commercial development, most of the students also need to spend a lot of effort for training, cost is relatively high, the actual effect is not good. The practice of enterprise often becomes the training course, the concrete learning effect is not obvious.

2. If a training base in the school, the school should not only to site and equipment cost, also need the enterprise personnel permanent school, the cost is also very high, if open commercial projects, and the corporate headquarters of communication cost is very high, so in the specific operation relatively rare. 
3. In addition to contact internship units, usually a class can only contact one or two units, otherwise it is very troublesome, so that the students learning content is very simple, if you get involved in project development, uneven levels of individual, team number is too large is also a very difficult to solve.

Based on some of the problems and difficulties, we began to explore the campus information construction and students' practice ability training. Use the mode of the teacher + students to participate in the construction and management of all kinds of information system in the campus network platform, and assign different items and tasks according to students' interest and level.. This mode is not only convenient for management, but also can give full play to the diversity of teach students in accordance with their aptitude, learning.

\section{Requirement analysis}

The launching of the campus information construction in full swing, which not only have such as Admissions Employment, financial, OA, reported to school leavers, HR research daily educational administration information system and teaching management, professional website, course website a lot of education and teaching and related information systems, and much of the content of these systems because it involves a wide range, closer to the connotation construction, high construction costs and short-term social benefits is not obvious. Therefore, it is often overlooked, the system is relatively low priority in the project. Our main purpose is to find the development progress in these systems is not particularly tight, the technical requirements are not particularly high for the project as our example project, through the organization of teachers + student participation, starting from the needs analysis around the project to carry out all aspects of the teaching activities, for example about the development process of the project in in software engineering, each link around specific projects and experiments to explain, in programming courses in a few representative function modules to specific about program design skills and experience in practice, part of all-weather participation in all aspects of software development, testing, maintenance and other work, is a student a full range of contact and understanding of software project development, and brewing these problems in the process are used to do a graduation design topic, to solve through a more in-depth study and research. This method can not only greatly improve the students practical ability to develop, but also simplify the student management, the school can also reduce development costs, enhance the capability for independent development, to achieve a win-win outcome.

\section{Instructional design}

We mainly from the following four teaching links, each teaching process and the campus information construction, the daily teaching work into the information construction of the various links of:

Theoretical teaching link. The concrete project and software engineering, software testing and relational database course to combine, the various sections of the concrete instance explain an informatization project in a part of the implementation of the content, by case teaching method will be of classroom teaching and the development of business combination, increase the students' interest in learning and understanding of the depth.

Practical teaching link. In web design, Java programming,. Net programming and related to the development of a series of courses on the machine part with specific projects of a module or page to teaching or training, to improve the students' practical ability, also can be result of practical training teaching process as a module or material of the actual project was carried out using.

Professional internship link. Practice will link into the development of informatization construction

of a subsystem or a sub module in the school, contains a short-term training, and take part in all aspects 
of the complete software development process to, into different groups according to different students interest and levels, each team is assigned different tasks, these tasks can be either demand analysis and design, coding and testing, or code for the are not familiar with the students can also document distribution control, training system and release, system operation and maintenance and so on other tasks.

Graduation design link. A local problem in the project training session after the actual information construction project exercise, you can select one as the graduation design topic, and then proceed to further research and processing, the problem solving method and the corresponding results as graduation design results.

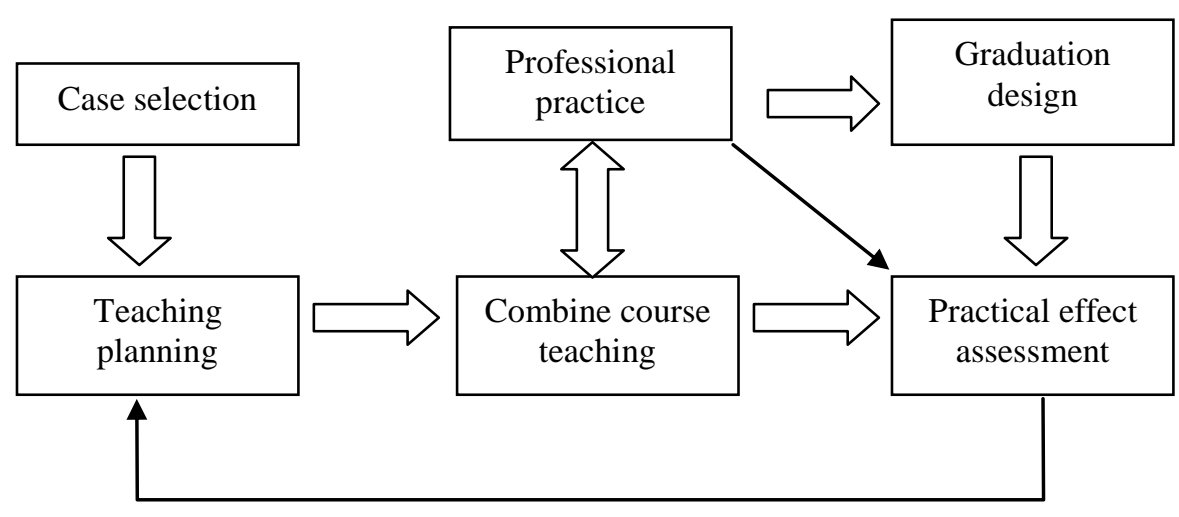

Feedback

Fig. 1 Project implementation flow chart

As shown in Fig. 2, our first choice, a good case, and then specify the corresponding teaching plan, will be combined in informatization construction and teaching and professional training, the construction results into the process of graduation design, formed a relatively complete teaching chain. After of course teaching, professional practice and graduation design and other aspects of the practice and effect evaluation, the evaluation results feedback to the planning aspects of teaching, thus forming a recursive iteration of the circulation system.

\section{Teaching practice}

Two grade practice semester skills internship, based on Java Web project training. At this time, the students have completed the relevant courses (Java language advanced programming, database principle and application and Web development technology (Java), etc.). Java based Web project training is based on the JSP and database development of a Web system, the purpose is to practice the content of the theory curriculum, but not the framework and other advanced technology. After a month of training, the students can master the project flow of the Web development, and have a further understanding of the common technology.

Graduation practice is divided into two parts of the project training and design, from the beginning of the three grade school year, the duration of the year. Practice sessions with third grade and fourth grade first semester even in training project, according to the direction of the students in the third grade selected, for the Java project training and Android project training two independent unit. Java direction of the project training is in the two grade school year on the basis of the practice, to do further expansion and strengthening. First is the basic theoretical knowledge Chuanjiang, which includes both before the 
students learned knowledge, such as HTML, CSS, JavaScript, Java, JSP, Oracle, but also they are not familiar with the content such as the MVC pattern, FreeMarker, webwork, spring. Android direction of the project training is through the development of some Android application case, to understand the development and application of APP, and master the application development technology based on Android platform. After the theoretical knowledge is explained, the students are trained to carry out the training of a small project to reach the goal of mastering the theoretical knowledge.. In the stage of large projects, student grouping, a real big system development, mode of enterprise management, the ultimate objective is to achieve mastery through a comprehensive study of all knowledge.

Graduation design started from the fourth grade in the latter half of the first semester, some coincidence and training project, require students to at the end of the training project and completed the graduation design proposal work. Graduation topic design is basically a continuation of the training project, guidance teachers in fully understanding based on the completion of the project students training to students issued for the ability of project, and to direct, to control the whole process of the graduation design, master schedule and ensure the graduation design of smoothly. Here are some of the interface screenshots of the project.
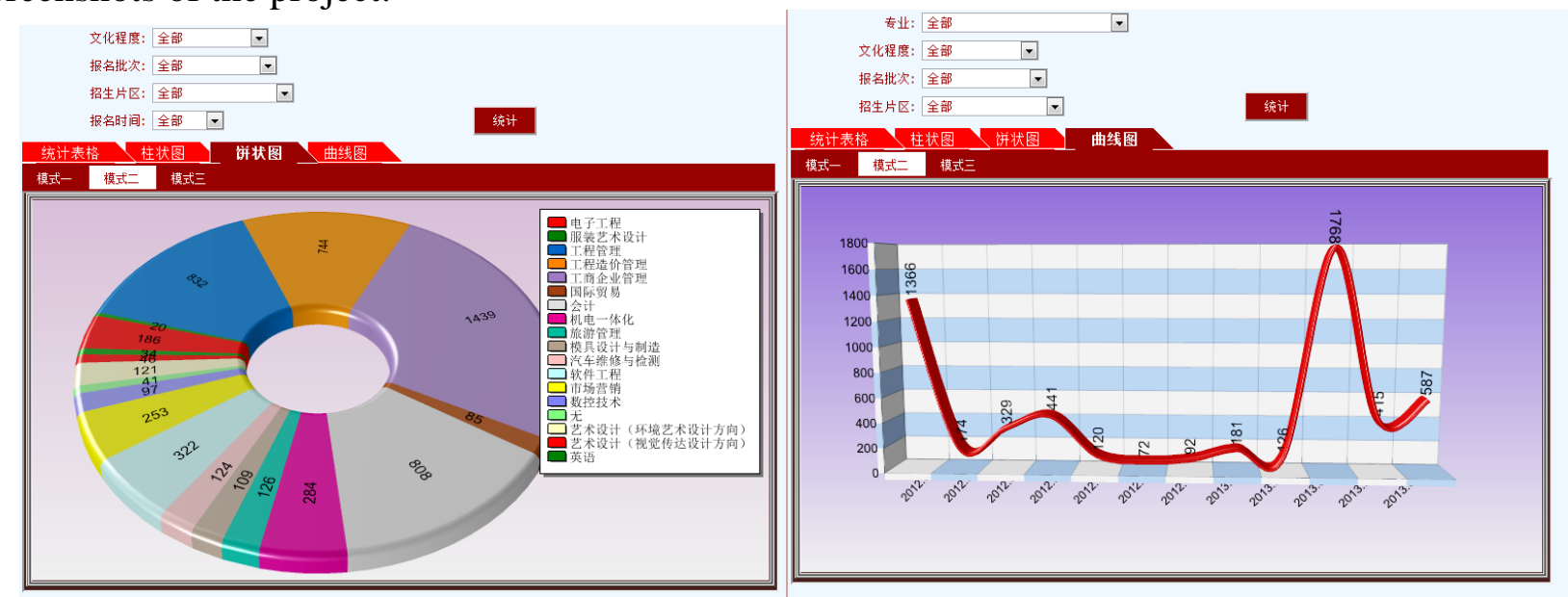

Fig. 2 Software interface screenshot

\section{Acknowledgment}

This work was supported by the project of "research and application project of education teaching and research and application" in Jiangxi Institute of Technology [JY1314]. The authors are grateful for the anonymous reviewers who made constructive comments.

\section{References}

[1] Joel Moses, My life, http://esd.mit.edu/Faculty_Pages/moses/moses_memoirs.pdf, 284-285.

[2] Massachusetts Institute of Technology.Undergraduate Research Opportunities[EB/OL]. http://www.mitadmissions.org/topies/learning/undergraduate_research_opportunities/index.shtml , 2010-8-25.

[3] Miguel F.Anjos, Kenneth N.McKay.Co-operative Education and Career Services Employment Process Review[R], 2007(5): 21 
[4] Sotiris Batsakis,Euripides G.M. Petrakis,Evangelos Milios. Improving the performance of focused web crawlers[J]. Data \& Knowledge Engineering . 2009 (10)

[5] Peng Tao,He Fengling,Zuo Wanli. A new framework for focused Web crawling[J]. Wuhan University Journal of Natural Sciences . 2006 (5)

[6] G. Almpanidis,C. Kotropoulos,I. Pitas. Combining text and link analysis for focused crawling-An application for vertical search engines[J]. Information Systems . 2006 (6)

[7] Alberto H. F. Laender,Berthier A. Ribeiro-Neto,Altigran S. da Silva,Juliana S. Teixeira. A brief survey of web data extraction tools[J]. ACM SIGMOD Record . 2002 (2)

[8] Vladimir M. Krasnopolsky,Michael S. Fox-Rabinovitz. Complex hybrid models combining deterministic and machine learning components for numerical climate modeling and weather prediction[J]. Neural Networks . 2006 (2)

[9] William E. Winkler. Methods for evaluating and creating data quality[J]. Information Systems . 2004 (7) [3] Monika R. Henzinger,Rajeev Motwani,Craig Silverstein. Challenges in web search engines[J]. ACM SIGIR Forum . 2002 (2)

[10] Peter W. Foltz,Sara Gilliam,Scott Kendall. Supporting Content-Based Feedback in On-Line Writing Evaluation with LSA[J]. Interactive Learning Environments . 2000 (2) 